\title{
The Underlying Factors Of Rural-Urban Migration In Southeastern Nigeria: A Study In Nsukka Region Of Enugu State
}

\author{
BASIL, U. EZE \\ Department Of Geography And Meteorology, Enugu State University Of Science And Technology (Esut), Enugu \\ State
}

\begin{abstract}
This research appraised the underlying factors of rural-urban migration in southeastern Nigeria with focus on Nsukka Region of Enugu state. It utilized the survey research design which involved the use of household questionnaires in data collection. The study covered 4 local government areas, 16 communities and 910 households. Data analysis was done with Principal Component Analysis (PCA). The PCA identified five underlying push factors of migration in the region to include: presence of impelled migration; poor income generating opportunities; escaping unfavourable conditions; transfer as a factor of migration and escaping conflict and insecurity of life. PCA result equally showed seven underlying dimensions that pull migrants to urban destinations namely: seek improved economic status; accessible destinations; join spouse; seek greater development; stay with relations; enjoy more convivial environment and engage in politics. it is found that the strength of push and pull factors are almost equal as determinants of rural-urban migration in the region as each of these groups of factors exert approximately $61 \%$ of pressure on the migrant to migrate out of the rural areas of the study area and also to in-migrate to the urban areas. Among the recommendations is that special incentives be offered to private firms and companies that locate in the rural areas of the region to boost employment opportunities and so downgrade rural out-migration.
\end{abstract}

Key words: underlying factors, rural-urban, migration

\section{Introduction}

Migration has been the third critical influence on population size, composition and distribution besides the population dynamics of birth and death or reproduction (Knox and Marston 2004). Migration because of its multi-faceted consequences, has gained elaborate attention in geography and according to Barclays (1972), it probably had more attention than any other topic in demography. The history of man from the stone-age to contemporary times abound with instances of population movements, not only as a means of restoring ecological balance, but also as a means of achieving better conditions of living, either in search of more food, better shelter or security and employment opportunities. However, according to Nwajiuba (2005), the pattern of migration has changed considerably overtime, from the search for space, especially in the middle ages to that of congestion in large cities in the modern age.

The migration phenomenon in Africa can be better understood within the context of political and historical evolution of African societies. The effects of colonization and decolonization on the economy and indirectly on migration are most visible when examined in the context of the pre-colonial, the colonial and the post-colonial era. West Africa has experienced a variety of migrations caused by population pressure, poverty, poor economic performance and endemic conflicts. Contemporary patterns of migration in West Africa are rooted in socio-economic, political and historical via cultural factors which have shaped the direction of movement and types of economic activities (Onwudinjo, 2012) Nigeria plays a key role in African migration. As Africa's demographic giant, Nigeria has become increasingly involved in international migration to Europe, America, Asia, the Gulf countries and South Africa. Yet, Nigeria is also a source and destination country with respect to migration within West Africa (Adepoju, 2004, Hass, 2006).

Migration follows a variety of patterns which expresses migration on space dimension. They include, urban-urban; urban-rural; rural-rural and rural-urban. This research is centred on rural-urban migration which is one of the patterns that expresses migration on a space dimension. Rural-urban migration constitutes one of the currents of internal migration in Nigeria and elsewhere. It involves the movement of people from rural areas to urban areas on permanent or semi permanent basis (Eze, 2015). This type of population movement is abundantly expressed in South-Eastern Nigeria of which Nsukka region is a salient part. It is a type of migratory movement in which the motive is not only to improve the movers livelihood opportunities and welfare, but also the livelihood improvements of those left behind in the rural area. (Eze, 2016).

Rural-urban migration results from the search for perceived or real opportunities as a consequence of rural-urban inequality in wealth (Sorenson, 2004; Madu, 2006). This inequality and or urban bias in 
development according to research findings over the years results from overwhelming concentration of wealth, assets, purchasing capacity, economic activities, and Variety of services in the urban centres as well as continued neglect of rural areas (Todoaro, 1998, 1985; Ellis, 2003, 2005; and Timalsina, 2007). Nevertheless researches have shown that the determinants of or propensity of migration differ from place to place and among migrants over time.

The determinants of migration even though diverse, may all be subsumed into push factors (reasons for leaving an area) and pull factors (reasons for moving into an area). Those factors may also be social, political, economic, environmental and cultural in nature (Macpherson, 2000; National Geographic, 2005). Environmental factors influencing migration include incidence of floods, earthquakes, droughts and weather. On the other hand, cultural determinants of migration involves quest for education and opportunities to follow lifestyles and hold beliefs foreign to migrant's place of origin, while social factors of migration are located in wars, conflicts, migrant networks, diseases and famines. Politically, people migrate because of perceived or real political advantages, administrative convenience and also because of ethnic and political persecution. Finally, employment, investment opportunities and improvement in livelihood status are some of the economic determinants of migration (Ajaero, 2013).

Ajaero (2013) identified migration as a livelihood strategy utilized by the poor especially rural dwellers. In Nsukka region, rural-urban migration is seen as a viable livelihood strategy and is highly encouraged because of the financial success believed to be associated with it. It is not strange in this region for some kindred to hold meetings to urge a youngman who stays on the village without any overt goal to move out like others and seek success elsewhere (Eze, 2014). Some micro studies in some communities of the region as Okolo (2008) study in Eha-Alumona community show that migration increases the status symbol of a migrant's household. Parents or relatives do boast of their children or relatives living in one big city or the other.

One does not usually expect a higher institution graduate to remain in the village since there is no economic opportunity for gainful employment for him there. He is expected to move out and look for means of livelihood in the urban area, not only to improve on his own wellbeing but the wellbeing of the family left behind. He is expected to seek improvement of the wellbeing of the family that invested so much on him to the extent of having to sell plots of land and some economic trees. School leavers equally seek higher educational opportunities and/or economic opportunities in urban areas. Low skilled workers equally do the same. Thus migration to urban areas from rural areas of Nsukka region is usually expected and sought out for especially for the educated, the business inclined and technical men. This is moreso as the rural areas of the region as is obtainable in most rural areas of Nigeria are deprived of socio-economic opportunities and infrastructural facilities.

From the foregoing, rural-urban migration is identified as a livelihood strategy adopted by rural dwellers and it is abundantly expressed in Nsukka region. This variant of the migration process has profound influence on the individual migrant, his household, sources and destination areas and equally holds a significant implication for proper urban planning and rural development. It therefore follows that a systematic insight into the rural-urban migration process and its determining factors (push and pull), as the present study is designed to achieve, would be imperative in designing more effective migration and development policies in Nigeria generally and in Nsukka region in particular.

\section{Theoretical Framework}

There exist different theoretical frameworks in which internal migration especially the variant of ruralurban migration has been modeled. Salient among these models and especially of significance for this present work is the; 'push-pull' theory of migration decision as proposed by Lee in 1966.

\section{The push-Pull Model}

Most studies have shown migration as the result of push and pull forces working on the individual (Fig. 1). In other words, people see places as having positive, negative, and neutral attributes that they use, either consciously or unconsciously, in calculating whether to move or not. Lee in 1966 developed the push-pull framework for the purpose of analyzing the volume of migration, the characteristics of migration and by extension the factors which generally prompt migration decision making process. He classified the factors which generally prompt migration into push and pull factors which are respectively repulsive and attractive forces. The framework forms the backbone in determining the various deteriorating socio-economic conditions in the place of origin which literally force people to move out. The basic assumption of the model is therefore that there exist push factors such as poverty, unemployment, dearth of basic socio-economic infrastructure and generally lack of economic opportunities which compel people to move out of their place of residence to another place of higher opportunities.

Migrant is attracted (pulled) to destinations with those facilities and opportunities which he lacks and wishes to have. Besides the push and pull factors, Lee equally identified the personal and intervening factors. 
The personal factors refer to the positive and negative conditions at the source and destination regions which the migrant consider favourable or unfavourable (Onyefuru 2009). The migrants move when the positive conditions outside are stronger than the negative conditions. The intervening factors, however act as a strong filter which affect many potential moves. Such factors which may hinder moving include distance, cost, natural barriers (hills, water bodies), social structures such as leadership position or influential title in the family or village etc.

The rural areas in Nigeria are perceived as places that lack basic socio-economic infrastructure and are ridden with poverty. The decision to move out of rural areas is therefore often hinged on the socio-economic inadequacies that exist in the rural source region. This sets up a trajectory or pattern of movement from places (rural) with 'push' endogenous factors (unemployment, dearth of socio-economic infrastructure, poverty etc) to the destinations (urban) with attractive exogenous factors (pull) of employment opportunities, accessibility and availability of socio-economic facilities, and better life generally. Consequently, the rural-urban migration pattern emerges from the dynamics of human mobility which the push-pull theory stands to explain in this work.

\section{Fig 1: Schematic of push-pull model}

\section{Origin and destination factors and intervening obstacles in migration}
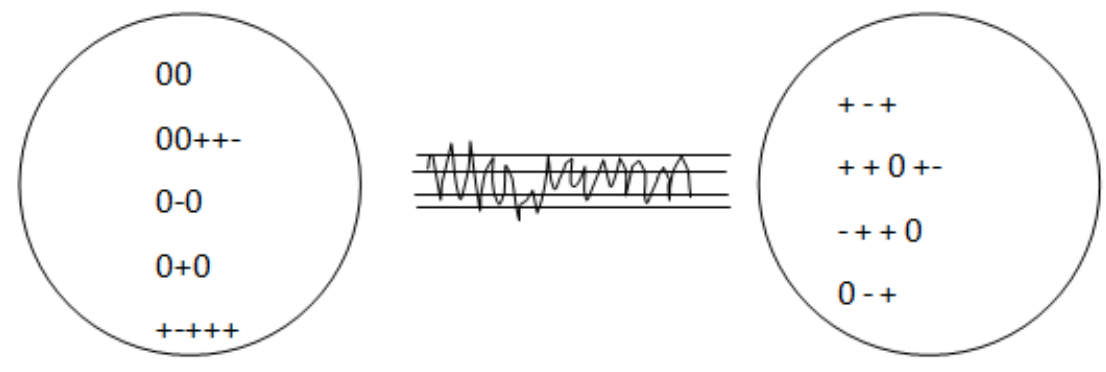

\section{Study Area}

\section{Materials And Methods}

The study area, Nsukka region is situated in Enugu state, southeastern Nigeria. The land surface of the region lies between latitudes $6^{\mathrm{O}} 30^{\mathrm{I}}$ and $7^{\mathrm{O}} 6^{\mathrm{I}}$ north and longitudes $6^{\mathrm{O}} 54^{\mathrm{I}}$ and $7^{\mathrm{O}} 54^{\mathrm{I}}$, and covers a total land area of 3,402 square kilometers (fig. 1). It is located on the northern part of southeastern Nigeria and comprises seven (7) local government areas namely: Igbo-Etiti, Igbo-Eze north, Igbo-Eze South, Isi-Uzo, Nsukka, Uzo-Uwani and Udenu. Nsukka region is chosen for this study because it exhibits as part of the variables homogenous socio-economic and cultural characteristics and falls within the same agro-climatic and other geography conditions. It is equally highly prone to rural-urban migrations. 
Fig. 2: Map of South-Eastern Nigeria showing the Study Area

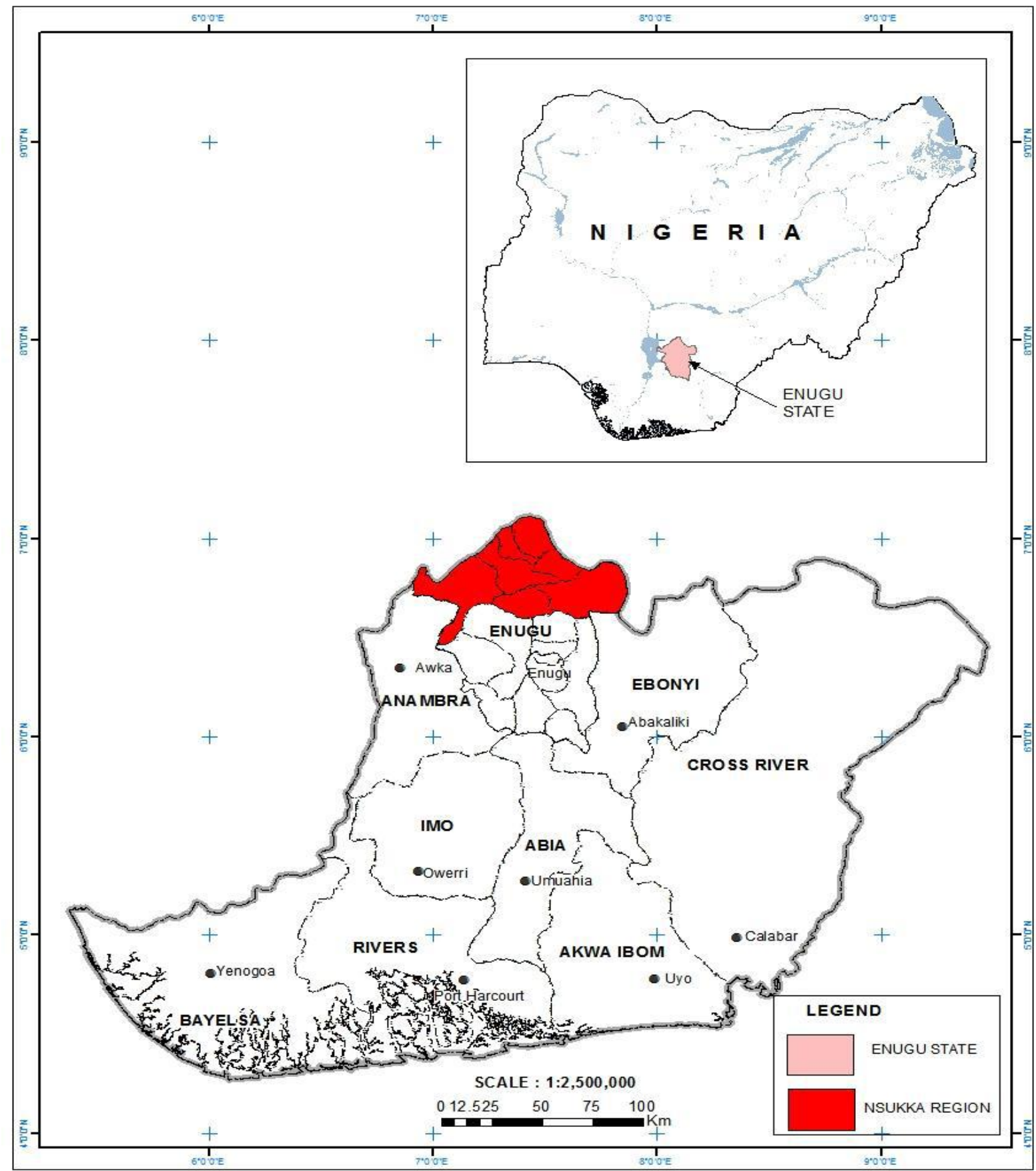

Source: Administrative Map of Nigeria, 11th Edition, Office of the Surveyed General of the Federation.

\section{Sample selection}

In this study, four local government areas were purposely selected out of seven that make up the region. The four local government areas are Igbo-Etiti, Isi-Uzo, Nsukka and Uzo-Uwani. The choice of these local government areas is based on their geographical locations in the region and their varying levels of population concentration. Isi-Uzo and Uzo-Uwani local government areas are located respectively on extreme eastern and western low-lying, agriculturally rich areas, each having low population size and concentration, while Igbo-Etiti and Nsukka local government areas are located on the Plateau and partly on escarpment, not so favoured with fertile plains for settlement and agriculture like the first two, yet with heavy population concentration. Equally Isi-Uzo and Uzo-Uwani local government areas represent more rural environments while Igbo-Etiti and Nsukka local government areas represent more urban environments. The choice of these local government areas therefore duly reflects the character of the region. 
Four communities are selected from each of the local government areas based on population size; thus two most populated communities and two least populated communities are chosen to reflect varying population concentration and sizes.

The sample size was statistically derived using Yaro's method (Onwe, 1998).

The formula is thus:

$$
\begin{array}{lllll}
\mathrm{n}=\mathrm{N} \\
\mathrm{I}+\mathrm{N}(\mathrm{e})^{2}- & - & - & - & -
\end{array}
$$

Where $\mathrm{n}=$ sample size

$\mathrm{N}=$ population size

$\mathrm{e}=$ level of significance or allowable error

$\mathrm{I}=\mathrm{a}$ constant

\section{Data Collection}

The main source of primary data was the structured questionnaire while literature from the published source formed the source of secondary data. The questionnaires were administered to heads of individual households or their spouses. The questionnaires were used to gather information on the factors determining rural-urban migration in the region. The total number of respondents was 910 which was gotten proportionately from the communities based on their population sizes.

\section{Data Analysis}

In analyzing the data, Principal Component Analysis (PCA) was used to extract the underlying components determining rural-urban migration to enable the determination of the general degree of importance and influence of the different factors. For the purpose of this research, it is recognized, variables with loadings exceeding 0.60 as depicting significant loadings. This is based on the size of our component loadings. The identified factors by the respondents which were used in the component analysis were as follows:

\section{Push Factors:}

X1 (To Escape Poor Infrastructure), X2 (To Escape Conflict At Home), X3 (To be Free From Parental Control), X4 (Due To Transfer), X5 (Due To Retirement), X6 (To Escape Flood/Erosion problem), X7 (Due To Poor Market For Trading), X8 (Due To Lack Of Employment Opportunities), X9 (Due To Poor Yielding Farmlands), X10 (Due To Marriage)

\section{Pull Factors}

X1(Seek Employment), X2(Further Education), X3(Join Spouse), X4(Join Parents Relations), X5(Enjoy Urban Life), X6(Enjoy Modern Facilities In Urban Areas), X7(Enjoy Better Health), X8(Live Near Friends And Relatives), X9(Earn Higher Income), X10(Practice Religious Faith), X11(Participate Better In Politics), X12(Due To Available Market For Trading), X13(Destination Is Easily Reached).

\begin{tabular}{|c|c|c|c|c|c|}
\hline \multirow{2}{*}{\multicolumn{6}{|c|}{$\begin{array}{l}\text { III. Results } \\
\text { Analysis of the Push Factors of Migration using Principal Component Analysis } \\
\text { Table 1: Rotated Component Matrixes }\end{array}$}} \\
\hline \multicolumn{5}{|c|}{\begin{tabular}{|cc} 
Components \\
\end{tabular}} & \\
\hline & I & II & III & IV & $\mathrm{V}$ \\
\hline $\mathrm{X} 1$ & 0.01 & -0.184 & 0.720 & -0.155 & 0.219 \\
\hline $\mathrm{X} 2$ & -0.013 & 0.032 & 0.006 & 0.055 & 0.949 \\
\hline $\mathrm{X} 3$ & -0.034 & 0.126 & 0.749 & 0.111 & -0.173 \\
\hline $\mathrm{X} 4$ & 0.044 & -0.041 & -0.068 & 0.813 & 0.013 \\
\hline $\mathrm{X} 5$ & 0.729 & 0.017 & 0.002 & 0.14 & -0.071 \\
\hline X6 & 0.631 & -0.028 & -0.064 & -0.196 & -0.015 \\
\hline $\mathrm{X} 7$ & -0.102 & 0.648 & -0.15 & -0.37 & 0.113 \\
\hline $\mathrm{X} 8$ & 0.04 & 0.811 & 0.069 & 0.174 & -0.044 \\
\hline X9 & 0.412 & -0.092 & -0.082 & -0.405 & -0.126 \\
\hline $\mathrm{X} 10$ & 0.747 & -0.001 & 0.064 & 0.067 & 0.1 \\
\hline Eigen Value & 1.674 & 1.139 & 1.126 & 1.093 & 1.025 \\
\hline$\%$ of Variance & 16.740 & 11.391 & 11.261 & 10.931 & 10.253 \\
\hline Cumulative \% & 16.740 & 28.131 & 39.392 & 50.323 & 60.576 \\
\hline
\end{tabular}

Source: Field work and Researchers Computation

From table 1, the factor analysis has succeeded in reducing the 10 independent variables to 5 components which yield the factors of rural out-migration in Nsukka region. The rotated PCA produced 5 components with a total of 10 significant loadings involving all the components. It is noted that the 10 
significant component loadings are positive and high which indicates strong and positive relationship between the variables and the components.

One possible explanation for the pattern of component loadings manifested by the rotated component matrix is that the issue of rural out-migration is multifaceted and no single component can explain a very high percentage of variance in its causal factors relative to others.

There are therefore 5 underlying determinants of rural out-migration in the study area. These underlying dimensions have a cumulative percentage variance of approximately $60.6 \%$. This means that these underlying factors explained $60.6 \%$ of the total variance in the determinants of rural out-migration in the region, leaving $39.4 \%$ of the explanation to other factors.

\section{Analysing the Pull Factors of Migration by Principal Component Analysis}

Table 2: Rotated Component Matrix

\begin{tabular}{|c|c|c|c|c|c|c|c|}
\hline & \multicolumn{7}{|c|}{ Component } \\
\hline & i & ii & Iii & iv & $\mathrm{v}$ & $\mathrm{Vi}$ & Vii \\
\hline $\mathrm{X} 1$ & .725 & .058 & .003 & .155 & -.049 & .057 & .151 \\
\hline $\mathrm{X} 2$ & -.491 & -.292 & .297 & .606 & -.048 & .117 & .271 \\
\hline $\mathrm{X} 3$ & -.040 & -.016 & -.845 & -.007 & .074 & .112 & .012 \\
\hline $\mathrm{X} 4$ & -.050 & .150 & .054 & .209 & .193 & -.609 & -.253 \\
\hline X5 & .136 & .181 & .117 & .643 & .084 & .097 & .122 \\
\hline X6 & .037 & .021 & -.066 & .216 & .031 & .732 & -.135 \\
\hline X7 & -.268 & .474 & .134 & -.118 & .173 & .638 & -.345 \\
\hline $\mathrm{X} 8$ & -.024 & .203 & .042 & .122 & .697 & -.077 & -.049 \\
\hline X9 & .019 & .204 & .347 & -.614 & .112 & .101 & .270 \\
\hline X10 & .020 & -.280 & -.127 & -.130 & .215 & -.002 & .117 \\
\hline X11 & -.003 & .082 & -.007 & .003 & .056 & .013 & .768 \\
\hline $\mathrm{X} 12$ & .690 & -.242 & .409 & -.036 & .079 & .064 & -.259 \\
\hline X13 & .066 & .752 & -.035 & .065 & -.049 & -.117 & .146 \\
\hline Eigen value & 1.216 & 1.161 & 1.149 & 1.121 & 1.107 & 1.095 & 1.080 \\
\hline$\%$ of variance & 9.353 & 8.927 & 8.835 & 8.623 & 8.514 & 8.420 & 8.304 \\
\hline Cumulative \% & 9.353 & 18.280 & 27.115 & 35.739 & 44.252 & 52.672 & 60.976 \\
\hline
\end{tabular}

Extraction Method: Principal Component Analysis.

Rotation Method: Varimax with Kaiser Normalization.

a. Rotation converged in 11 iterations.

A PCA was conducted to reduce the pull factors to more compacted factors. To achieve this, a rotation method based on Varimax with Kaiser Normalization was adopted. The result obtained converged in 11 iterations, thereby reducing the 13 factors to 7 independent components. The 7 components yield the underlying factors that determine the factors that pull migrants to urban areas. These altogether yielded $60.9 \%$ cumulative percentage variance. This implies that these 7 underlying factors explained approximately $61 \%$ of the total variance in the determination of rural migrants pull to urban areas, leaving $39 \%$ to other factors.

\section{Discussions}

Table 1 as already made known shows the results of PCA of push factors of migration with 5 components extracted. Component 1 has an Eigen value of 1.674 and accounts for $16.740 \%$ of the total variance. It has significant loadings on three variables: x5(Due to retirement), x6(to escape flood/erosion problems), and x10(Due to marriage). All these variables exert pressure on somebody to migrate but he could decide not to, therefore the underlying component here becomes the presence of impelled migration.

Component II with an Eigen value of 1.139 explains $11.391 \%$ of the total variance. It loads significantly on variables $\mathrm{x} 7$ (due to poor market for trading) and x8(due to lack of employment opportunities). The underlying factor of out-migration here is therefore poor income generating opportunities.

Component III contributes to $11.261 \%$ of total variance and has an Eigen value of 1.126 and has two variables with significant loadings. The variables are x1(to escape poor infrastructure) and $\mathrm{x} 3$ (to be free from parental control), the underlying component becomes escaping unfavourable conditions as a factor of migration in the study area.

Component IV loads highly on one variable and that variable is $\mathrm{x} 4$ (due to transfer). It has an Eigen value of 1.093 and explains $10.931 \%$ of the total variance. The underlying component here is transfer as a factor of migration. 
Component V loads significantly on one variable - x2(to escape conflict at home). It has an Eigen value of 1.025 and percentage variance of 10.253. The underlying component is escaping conflict and insecurity of life as a factor of migration in the region. We have from the factor analytic approach been able to identify the five distinct components (underlying dimensions) which are the underlying push factors of migration in Nsukka region.

The results of the PCA of Pull Factors of migration shown in table 2 reveals 7 underlying components that attract migrants of the study area to urban areas. Decomposing these 7 underlying factors, component 1 shows significant loadings on two variables X1(seek employment) and X12(Due to available market for trading). It has an Eigen value of 1.216 and accounts for $9.353 \%$ of the total variance. The underlying component here becomes seek improved economic status.

Component II has an eigen value of 1.161 and explains $8.927 \%$ of total variance. It loads significantly on variable X13 (Destinations is easily reached). The underlying component is therefore accessible destinations.

Component III with an eigen value of 1.149 , explains $8.835 \%$ of total variance and significantly loads on variable X3 (join spouse). The underlying component becomes join Spouse as a pull factor of migration. Component IV has an eigen value of 1.121 and explains $8.623 \%$ of total variance. It has a significant loading on three variables: X2 (further education); X5 (enjoy urban life) and X9 (earn higher income). The underlying component becomes seek greater development. Component V significantly loads on variable X4 (join parents/relations) and variable X8 (Live near friends and relatives. It has an eigen value of 1.107 and explains $8.514 \%$ of total variance. The underlying component is therefore stay near relatives. Components VI explains $8.420 \%$ of the total variance and has an eigen value of 1.095 . It loads significantly on two variables namely X7 (enjoy better health) and X8 (enjoy modern facilities in urban areas). The underlying component is thus, enjoy more convival environment. Component VII loads significantly on variable X11 (participate better in politics). It has an eigen value of 1.080 and explains $8.304 \%$ of total variance. The underlying component is seen as engage in politics.

The factor analysis has produced 7 underlying factors that pull migrants to the urban areas from the rural areas of Nsukka region.

The push-pull model, already explained in the section on theoretical framework, assumes that ruralurban migration which this study addresses is pummelled and sustained by negative and repulsive forces in rural areas which push people out of such areas and positive and attractive forces which pull people into urban areas. This assumption is clarified in Nsukka region where it is found that there exist in her rural areas such push factors as poverty, unemployment, dearth of basic socio-economic infrastructure and generally lack of economic opportunities which compel the rural inhabitants to out-migrate. They are equally pulled or attracted to the urban destinations in different parts of the country with higher opportunities where facilities and opportunities to be availed of are available. Such opportunities include employment, accessibility and availability of socioeconomic facilities and better life generally.

A PCA result identifies five underlying push factors of rural-urban migration and these factors are: presence of impelled migration, poor income generating opportunities, escaping unfavourable conditions; transfer as a factor of migration and escaping conflict and insecurity of life. Equally, principal component analysis on pull factors of migration brought out seven underlying Pull factors and they include: seek improved economic status, accessible destinations, join spouse; seek greater development; stay near relatives; enjoy more convivial environment; and engage in politics. From the foregoing results, it is clear that the overriding push factors in the study area is poor socio-economic opportunities and infrastructural facilities and the overriding pull factors is availability of same in urban areas of destination by migrants. It is equally clear that the strength of push and pull factors are almost equal as determinants of rural-urban migration in the region. This is understandable by the PCA results of both groups of factors which show that the underlying push factors explained $60.6 \%$ of the total variance in the determinants of rural out-migration and the underlying pull factors explained $60.9 \%$ of the total variance. So each of these groups of factors exert approximately $61 \%$ of pressure each on the migrant to migrate out of the rural areas of the study area and also to in-migrate to the urban areas.

One must however note that there are other factors which when cumulated impacts strongly on outmigration in the region. What this implies is that the push and pull may not always be so easy to determine. This is because at each point, the pushes and pulls are at work and may not be summed up in a simple fashion to arrive at a mathematical decision. Not all minuses and pluses are of the same magnitude as manifest in the findings. Somebody can actually be pulled to another location to get a higher economic opportunity even though his source region is comfortable. There are also intervening obstacles which can prevent a pull even when the source region is hostile - such as cost of movement, distance and even non-availability of information of opportunities elsewhere. Thus in Nsukka region even though out-migration persists, stayers are also available. 


\section{Recommendations}

Based on the findings of the study and observations, recommendations are made as hereby presented.

i One of the major factors indicted for rural out-migration in Nsukka region is lack of job opportunities, yet in the region there exist diverse resources that could be harnessed to enhance industrialization. Special incentives, besides, infrastructural development, should be offered to private firms and companies that are located in rural areas of Nsukka region to boost employment opportunities for the people by harnessing the local resources. Such incentives could include tax reliefs, free lands to site firms, easier access to bank loans. These will boost employment opportunities and downgrade out-migration.

ii The principal occupation of rural dwellers of Nsukka region as elsewhere is farming. It is therefore suggested that government should awaken effort practically to improve agricultural productivity in the region. The input subsidization strategy of government should be revitalized, so that fertilizers, implements, seedlings and affordable credit facilities can be made accessible to farmers to retain people in rural regions. Also one suggests a revamping of the farm-settlement scheme for school leavers taking note to deal or avoid the ills that led to its scrapping before. This time, graduates of tertiary institutions should be the candidates while government gives full comprehensive attention for up to three to five years before the beneficiaries could be left to be independent to operate. In Nsukka region for instance, the eastern and western lowlands are potentially rich agricultural region waiting to be effectively harnessed. They therefore constitute veritable sites for farm settlement schemes. All these will lead to increased agricultural productivity absorb rural labour force, attract agro-based industries, thereby creating more job openings and wealth and so restrain out-migration.

iii This study found that many communities that have educational institutions including tertiary institutions close or within them had less of their migrants migrating on account of pursuit of education. It therefore follows that in order to reduce the tide of rural out-migration more schools and colleges should be established within or close to the rural areas at strategic locations. This should be pursued by both private and public concerns. A follow-up from the above is that vocational training centres should be established in the rural areas for skill acquisition by youths since not all youths are academically oriented. The establishment of such training centres will equally enable the youths acquire training within the rural setting without being entirely de-linked from farming.

\section{Conclusion}

This study appraised the push and pull factors determining rural-urban migration in Nsukka region. The reasons for migrations were categorized into push and pull factors. The factor analysis on the push factors of migration brought forth five underlying dimensions which explained $60.6 \%$ of the total variance of the causes/pushes of rural out-migration. Equally a PCA on pull factors of migration revealed seven underlying components that explained approximately $61 \%$ of the total variance of the factors that pull migrants from rural areas of Nsukka region to different urban areas of the country. Some recommendations are made which if considered and implemented by the relevant concerns will not only control rural-urban migration in the region but will usher in improved livelihood and development generally.

\section{References}

[1]. Adepoju, A. (2004): "Changing Configurations of Migration in Africa". Migration Information Source Available on-line

[2]. Ajaero, C.K. (2013): The Spatial Impacts of Rural-Urban Migration on Rural Livelihoods in SouthEastern Geo-Political zone of Nigeria. A ph.D submitted to the Dept. of Geography UNN.

[3]. Barclay, G.N. (1972): Techniques of Population Analysis. John Willey and Sons, New York.

[4]. Ellis F. (2005): Small farms, Livelihood Diversification and Rural Urban transitions, Strategic Issues in Sub-Saharan Africa. School of Development Studies, University of East Anglia, U.K.

[5]. Ellis, F. (2003): A. Livelihood Approach to Migration and Poverty Reduction" A Paper Commissioned by the Department for International Development (DFID) overseas Development studies Vol. 35, No. 1; pp 1-38.

[6]. Eze, B.U. (2014b).Appraisal of the Impacts of Rural-Urban Migration on the Livelihoods of Rural Households in Nsukka Nigeria. An Unpublished Ph.D. thesis, Department of Geography and Meteorology, Enugu State University of Science and Technology, Enugu.

[7]. Eze, B.U. (2015). Rural-Urban Socio-Economic Links in Foron District of Jos Plateau, North Central Nigeria. International Journal of Science, Environment and Technology. Vol. 5, No. 6

[8]. Eze, B.U. (2016). The Impacts of Rural-Urban Migration on ownership of Household Property Assets in Nsukka Area, Southeastern Nigeria. International Journal of Science, Environment and Technology. Vol.5, No. 1.

[9]. Haas, D.H. (2006): "International Migration and National Development: the Case of Nigeria". A Report for Rad Boud University. Nijmegen

[10]. Knox, P and Marston, S (2004): Human Geography. Pearson Education. INC: New Jersey.

[11]. Macpherson, C. (2000): "Some Social and Economic Consequences of Migration" A Curriculum Paper for Samoa Prepared for UNESCO Social Science Programme.

[12]. Madu , I.A., (2000): Rural Markets as a Factor of Rural Development in Nsukka Region, Southeastern Nigeria, Unpublished PhD Thesis, Department of Geography, University of Nigeria, Nsukka.

[13]. Madu, I.A. (2006): "Spatial Inequality in Nigeria: The Imperative of Geographic Perspective in the Development Process" Journal of Social and Economic Development Vol. 8 No. 2 pp 105-120. 
[14]. National Geographic (2005): "What is Human Migration” Human Migration Guide. pp 6-8

[15]. Newman J.L and Matzke, G.C. (1984): Population Patterns, Dynamics, and Prospects. Prentice Hall Inc., New Jersey.

[16]. Nwajiuba, C. (2005): "International Migration and Livelihoods in Southeastern Nigeria", Global Migration Perspectives. Geneva, No. 50

[17]. Okolo, E.O. (2008): The socio-economic effects of out-migration on Eha-Alumona Community, Nsukka LGA. A B.Sc. Thesis submitted to Department of Geography and Meteorology ESUT.

[18]. Onwe, O.J (1998): Elements of project and dissertation writing: A guide to effective Dissertation Report. Lagos: Impressed books.

[19]. Onwudinjo, I.E (2012): The political economy of Intra-Rural Migration and Development in Nigeria: A Study of Farmers and Artisans in Ezeagu Local Government of Enugu State. An Unpublished M. Sc Report Submitted to the Institute for Development Studies, University of Nigeria.

[20]. Onyefuru, U.K. (2009): Causes and consequences of rural out-migration in Oji River LGA of Enugu state. Project submitted to the Department of Geography, University of Nigeria, Nsukka.

[21]. Sorenson, N.N (2004): "The Development Dimension of Migrant Remittances: Toward a General Typology", Paper Presented at International Forum on Remittances, Washing, June, 28-30, 2004

[22]. Timalsina K.P. (2007): Rural-Urban Migration and Livelihood in the Informal Sector: A Study of Street Vendors of Kathmandu Metropolitan City, Nepal. Unpublished Master of Philosophy Thesis in Development Studies Submitted to Department of Geography Norwegian University of Science and Technology (NTNU).

[23]. Todaro M.P. (1998): Economic Development in the Third World. New York: Longman.

[24]. Todaro M.P., (1969): "A model of Labour Migration and Urban Unemployment in Less Developed Countries" American Economics Review. Vol. 59.

[25]. Todaro, M.P (1985): "Rural-Urban Migration: Theory and Policies", in Economics for a Developing World, Longman, Second Edition. 